Ege Tıp Dergisi / Ege Journal of Medicine 2019; 58 (4): 330-335

\title{
Trakya Üniversitesi Tıp Fakültesi Genetik Hastalıklar Tanı Merkezinde beta talasemi minor kliniği ile incelenen bireylerde görülen beta globin mutasyonları ve sıklığı
}

\author{
Beta globin mutations in beta thalassemia minor patients in Genetics Diagnosis Center \\ of Trakya University Faculty of Medicine
}

Sinem Yalçıntepe

Trakya Üniversitesi Tıp Fakültesi, Tıbbi Genetik Anabilim Dalı, Edirne, Türkiye

\section{Öz}

Amaç: Beta talasemi, Beta Globin (HBB-Hemoglobin Beta Locus) genindeki dört yüzden daha fazla mutasyonun neden olduğu otozomal resesif kalıtımlı genetik bir hastalıktır. Trakya Bölgesinde $H B B$ geni mutasyonlarını ve sıklığını saptamak amacı ile beta talasemi minor kliniği ile Genetik Hastalıklar Tanı Merkezimize gönderilen 236 hasta çalışmaya dahil edildi.

Gereç ve Yöntem: Çalışmaya dahil edilen tüm olgulardan elde edilen periferik kan örneklerinden, sanger sekans yöntemiyle beta globin geni dizi analizi yapıldı.

Bulgular: $97(\% 41,1)$ hastada 98 adet heterozigot $H B B$ geni mutasyonu saptandı. HBB geni mutasyonları IVS I.110 (G>A) (\%28,6), Codon 39 (C>T) (\%18,4), IVS1-1G>A, c.92+1 (G>A) (\%8.2), IVSII-745 (C>G) $(\% 7,1)$, IVS-I-6 (T>C) $(\% 5,1)$, Codon $8(-A A)$, c.25.26.delAA $(\% 4,1)$, Codon $44(-C)(\% 4,1)$, Hb F Carlton (\%3,1), Cd 5 [-CT], c.17.18delCT (\%3,1), cd8/9+G, c.27_28insG, c.27dupG (\%3,1), c.364 G>A, p.Glu122Lys (\%3,1), c.-31 C>T (\%3,1), CD6 -A, 20delA (\%2), c. ${ }^{*}+111 A>G$ (PolyA) (A>G) (\%2), IVS-II-1 (G>A), c.315+1 G>A (\%1), c.30.31insT, p.Ala11Cysfs (\%1), CD26 G>A (Hb E), c.79 G>A (\%1), CD15 G>A, c.48 G>A (\%1) olarak tespit edildi. Çalışmamızda Trakya Bölgesi'nde on sekiz farklı $H B B$ geni mutasyonu saptadık.

Sonuç: Çalışma sonuçlarımız beta talasemi taşıyıcılığının Türkiye coğrafyasında sadece Ege, Akdeniz ve Güneydoğu Anadolu Bölgesinde değil, Trakya Bölgesinde de sık olduğunun bilgisini literatüre sunmaktadır.

Anahtar Sözcükler: Beta talasemi, Trakya Bölgesi, mutasyon, anemi.

\section{Abstract}

Aim: Beta thalassemia is an autosomal recessive genetic disorder caused by more than four hundred mutations in the beta globin (HBB-Hemoglobin Beta Locus) gene. 236 patients referred to our Genetic Disorders Diagnosis Center with beta thalassemia minor clinic to determine the frequency of HBB gene mutations in the Thrace Region.

Materials and Methods: Beta globin genetic analysis was performed by sanger sequence from peripheral blood samples obtained from all included cases.

Results: 98 heterozygous HBB gene mutations were detected in 97 (41.1\%) patients. HBB gene mutations were IVS I.110 (G>A) (28.6\%), Codon 39 (C>T) (18.4\%), IVS1-1G>A, c.92+1 (G>A) (8.2\%), IVS II.745 (C>G) (7.1\%), IVS I.6 (T>C) (5.1\%), Codon 8 (-AA), c.25.26.delAA (4.1\%), Codon $44(-C)$ (4.1\%), Hb F Carlton (3.1\%), Cd 5 [-CT], c.17.18delCT (3.1\%), cd8/9+G, c.27_28insG, c.27dupG (3.1\%), c.364 G>A, p.Glu122Lys (3.1\%), C. $31 \quad C>T$ (3.1\%), $C D 6-A, \quad$ c.20delA (3.1\%), $\quad{ }^{*}+111 A>G$ (PolyA) (A>G) (2\%), IVS-II-1 (G>A), c.315+1 G>A (1\%), c.30.31insT, p.Ala11Cysfs (1\%), CD26 G>A (Hb E), c.79 $G>A(1 \%), C D 15 G>A, C .48 G>A(1 \%)$. In our study, we found eighteen different HBB gene mutations in the Thrace region.

\footnotetext{
Yazışma Adresi: Sinem Yalçıntepe

Trakya Üniversitesi Tıp Fakültesi, Tıbbi Genetik Anabilim Dalı,

Edirne, Türkiye

E-mail: sinemyalcintepe@gmail.com

Makalenin Geliş Tarihi: 16.07.2018 Kabul Tarihi: 07.09.2018
} 
Conclusion: Our results are presenting that beta thalassemia trait is not frequent only in Aegean, Mediterranean and Southeast Anatolia region in Turkey geography, but also frequent in the Thrace region to the literature.

Keywords: Beta thalassemia, Thrace region, mutation, anemia.

\section{Giriş}

Talasemi dünyada en sık görülen genetik hastalık olarak öngörülmektedir. En sık görülen tipleri alfa $(\alpha)$ ve beta $(\beta)$ talasemilerdir. Beta talasemi, Türkiye ve diğer birçok Akdeniz ülkesinde sık gözlenen, otozomal resesif kalıtılan tek gen hastalığıdır (1). Beta-globin (HBB) geni 11. kromozomun kısa kolu üzerinde (11p15.4) yer almakta ve üç ekzon, iki intron içermektedir. $H B B$ gen mutasyonları beta talasemi, orak hücreli anemi ve anormal hemoglobin varyantlarına neden olmaktadır (2). Beta-talasemi hemoglobin tetramerindeki beta globin zincirinin yokluğu (beta $\left.{ }^{0}\right)$ veya azalması $\left(\right.$ beta $^{+}$) ile karakterizedir. Beta $^{0}$ ve beta $^{+}$zincir yapılarına sahip beta talasemi minör (beta-talasemi taşıyıcısı) olan bireylerin klinik olarak asemptomatik olması beklenmektedir. Laboratuvar bulgusu olarak hipokrom mikrositer anemi, $\mathrm{HbA} 2$ ve $\mathrm{HbF}$ artışı beklenmekte, bazen bu bireylerde ağır anemi de görülebilmektedir.

Beta talasemi prevalansı Akdeniz ülkeleri, Güneydoğu Çin, Asya, Orta Doğu, Uzak Doğu ülkeleri yanı sıra Afrika'nın kuzey ülkelerinde ve Güney Amerika'da yüksektir. En yüksek taşıyıcı sıklığı Kıbrıs (\%14), Sardunya $(\% 10,3)$ ve Güneydoğu Asya'da bildirilmiştir (3). Türkiye genelinde taşıyıcılık oranı \%2,1 olmakla birlikte, bu sayı Türkiye'nin bazı bölgelerinde \%10'a kadar çıkmaktadır (4). Beta talasemi taşıyıcııı̆ı veya hastalığının saptanması, erken prenatal tanı, preimplantasyon genetik tanı ve tedavi protokolleri için önemlidir. $H B B$ geninde nokta mutasyonları (missense, nonsense) ile sıkça karşılaşıldığı gibi delesyonlar ve insersiyonlar da görülebilmektedir. Nokta mutasyonları RNA transkripsiyonunun başlamasını, RNA stabilitesini önleyerek normal RNA globin sentezini önler, frameshift mutasyonlar ise translasyonu bloke eder (5). Bu genetik değişikliklerin analizi için günümüzde DNA dizi analizi çok yaygın kullanılmakta, mutasyonlar taranmakta, yeni mutasyonların da saptanmasını sağlamaktadır. Sık görülen bilinen mutasyonların analizi için revers dot-blot hibridizasyon yöntemi kullanılabilmektedir. Daha nadir kullanılan yöntemler ise, allele özgü primer analizleri (ARMS), oligonükleotid hibridizasyonu, restriksiyon endonükleaz analizidir.

Bugüne kadar dünyada $H B B$ geninde beta talasemiye neden olan 400 'den fazla mutasyon olduğu bildirilmiştir (2). Bunlardan 40 farklı mutasyon tipi toplam mutasyonların \%90'ını oluşturmaktadır (2). Akraba evliliklerinin sıklığı ve yüksek doğum hızı, Türkiye'de beklenenin de üzerinde beta talasemi taşıyıcısı ve/veya hastası olmasının temel sebebidir. Ülkemizde en sık rastlanılan beta talasemi mutasyonları; IVS I-110 (\%40), IVS I-6 (\%7,14), IVS I-1 $(\% 7,14)$ ve IVS II$745(\% 4,28)$ olarak bildirilmiştir $(1,4)$. Talasemi yönetiminde ülkelerin hemoglobinopati tarama programlarında genotiplendirme yöntemlerini kullanmakla birlikte tarama ve tanı yöntemleri ile fenotipik değişkenliklerin gösterilmesi önemlidir. Çalışmamızda Trakya Bölgesinde HBB geni mutasyonları ve sıklığı araştırılarak, literatüre katkı sağlanması amaçlandı.

\section{Gereç ve Yöntem}

Çalışmaya Ocak 2014-Aralık 2017 tarihleri arasında beta talasemi kliniği ile Genetik Hastalıklar Tanı Merkezimize gönderilen 236 hasta dahil edildi. Hastalardan EDTA'ı tüpe $2 \mathrm{ml}$ periferik venöz kan alınarak, genomik DNA eldesi kullanılan kitin protokolüne uygun olarak yapıldı [EZ1 Advanced Instruments, Qiagen, Hilden, Germany]. $H B B$ genine ait ekzon ve intron bölgeleri kullanılan kitin protokolüne uygun olarak PCR ile amplifiye edildi [GML AG, Wollerau / Switzerland]. Elde edilen amplikonlar agaroz jelde bant paternleri dikkate alınarak kontrol edildi. Uygun olan amplikonların Sanger Sekans yöntemi kullanılarak nükleotid dizleri belirlendi [ABI 3130 Avant system, Applied Biosystems, Grand Island, NY 14072, USA]. Elde edilen sonuçlar SeqScape v2.7 yazılım programı kullanılarak analiz edildi (Transcript: NM_000518.4, ENST00000335295).

Beta talasemi minor kliniği olan ve heterozigot genotipte olması beklenen bireylerde çalışmaya dahil edilme kriteri olarak $\mathrm{HbA}$ düzeyinin $\% 95,5$ 'in 
altında; $\mathrm{HbA} 2$ düzeyinin \%3,5'in ve/veya $\mathrm{HbF}$ düzeyinin \%1'in üzerinde olması dikkate alınmıştır.

\section{Bulgular}

Yaş ortalaması 13.88 olan 236 hastanın (123 erkek, 113 kadın) 97'sinde (\%41,1) toplam 98 mutasyon belirlenmiştir. Beta talasemi minor olarak refere edilen hastalarda IVS I.110 (G>A) $(\% 28,6)$, Codon 39 (C>T) $(\% 18,4)$, IVS1-1G>A, c.92+1 $(\mathrm{G}>\mathrm{A})(\% 8,2)$, IVS $1 \mathrm{l} .745(\mathrm{C}>\mathrm{G})(\% 7,1)$, IVS 1.6 $(\mathrm{T}>\mathrm{C}) \quad(\% 5,1)$, Codon 8 (-AA), c.25.26.delAA $(\% 4,1)$, Codon $44 \quad(-\mathrm{C}) \quad(\% 4,1)$, Hb F Carlton $(\% 3,1)$, Cd 5 [-CT], c.17.18delCT $(\% 3,1)$, cd8/9+G, c.27_28insG, c.27dupG $(\% 3,1), \quad$ c.364 G>A, p.Glu122Lys (\%3,1), c.-31 C>T (\%3,1), CD6 -A, c.20delA (\%3,1), c. ${ }^{*}+111 \mathrm{~A}>\mathrm{G}$ (PolyA) (A>G) (\%2), IVS-II-1 (G>A), c.315+1 G>A (\%1), c.30.31insT, p.Ala11Cysfs (\%1), CD26 G>A (Hb E), c.79 G>A (\%1), CD15 G>A, c.48 G>A (\%1) mutasyonları heterozigot olarak tanımlanmıştır (Tablo-1). Sadece bir olguda, Codon 39 (C>T) ve Hb FCarlton bileşik heterozigotluğu saptandı.
Mutasyonlar hastaların kliniği ile uyumlu bulunmuş olup mutasyon saptanmış hastalar beta talasemi minor tanısı almıştır. Beta talasemi minor ön tanısı ile tetkik edilen 139 hastada beta globin mutasyonu saptanmamıştır.

\section{Tartışma}

Beta talasemi tüm dünyada önemli bir sağlık sorunu olarak kabul edilmektedir. Her yıl yedi milyondan daha fazla çocuk, genetik bir hastalık veya konjenital anomali ile doğmaktadır, yaklaşık 320.000 bebeğin ise klinik bulguların eşlik ettiği bir hemoglobin hastalığı ile doğduğu, 30.000 çocuğun beta talasemiden etkilendiği bildirilmektedir $(6,7)$. $\mathrm{Bu}$ doğumların \% 80'i gelişmekte olan ülkelerde gerçekleşmektedir. Heterojen moleküler mekanizmalardan kaynaklanan beta talasemi tedavisinde kan transfüzyonları, demir şelasyon tedavisi ve kemik iliği transplantasyonu uygulanmaktadır. Yüksek maliyetler sebebiyle, güvenli kan transfüzyonlarına ve demir şelasyon tedavilerine ulaşmak her hasta için mümkün olmamaktadır (8).

Tablo-1. Çalışmamızdaki beta globin geni mutasyon dağılımları.

\begin{tabular}{lll}
\hline Mutasyon & Sayı & Oran (\%) \\
\hline IVS I.110 (G>A) & 28 & 28,6 \\
Codon $39(C>T)$ & 18 & 18,4 \\
IVS1-1G>A, c.92+1 (G>A) & 8 & 8,2 \\
IVS II.745 (C>G) & 7 & 7,1 \\
IVS I.6 (T>C) & 5 & 5,1 \\
Codon 8 (-AA), c.25.26.delAA & 4 & 4,1 \\
Codon 44 (-C) & 4 & 4,1 \\
Hb F Carlton & 3 & 3,1 \\
Cd 5 [-CT], c.17.18deICT & 3 & 3,1 \\
cd8/9+G, c.27_28insG, c.27dupG & 3 & 3,1 \\
c.364 G>A, p.Glu122Lys & 3 & 3,1 \\
C.-31 C>T & 3 & 3,1 \\
CD6 -A, c.20delA & 3 & 3,1 \\
C. ${ }^{*}+111$ A $>$ G (PolyA) (A>G) & 2 & 2 \\
IVS-II-1 (G>A), c.315+1 G>A & 1 & 1 \\
c.30.31insT, p.Ala11Cysfs & 1 & 1 \\
CD26 G>A (Hb E), c.79 G>A & 1 & 1 \\
CD15 G>A, c.48 G>A & 1 & 1 \\
Toplam & 98 & 100 \\
\hline
\end{tabular}


Tablo-2. Trakya Bölgesinde saptanmış olan HBB gen mutasyonlarının Türkiye'de Ege, Hatay, Orta Anadolu Bölgeleri ve Adana ilinde yapılmış olan çalışma sonuçları ile karşılaştıııması.

\begin{tabular}{|c|c|c|c|c|c|}
\hline HBB Gen Mutasyonları & $\begin{array}{c}\text { Çalışmamız } \\
\text { Trakya Bölgesi }\end{array}$ & $\begin{array}{l}\text { Hatay } \\
\text { Bölgesi }\end{array}$ & Ege Bölgesi & $\begin{array}{l}\text { Orta Anadolu } \\
\text { Bölgesi }\end{array}$ & Adana \\
\hline IVS I.110 (G>A) & $\% 28,6$ & $\% 30,10$ & $\% 41,7$ & $\% 40,88$ & $\% 35,14$ \\
\hline Codon $39(\mathrm{C}>\mathrm{T})$ & $\% 8,4$ & $\% 5.37$ & $\% 4,6$ & $\% 2,91$ & $\% 5,94$ \\
\hline $\begin{array}{l}\text { IVS1-1G>A, c.92+1 } \\
(G>A)\end{array}$ & $\% 8,2$ & $\% 9,60$ & $\% 8,9$ & $\% 5,73$ & $\% 8,66$ \\
\hline IVS II.745 (C>G) & $\% 7,1$ & $\% 3,22$ & $\% 8,6$ & $\% 6,20$ & $\% 2,22$ \\
\hline IVS I.6 (T>C) & $\% 5,1$ & $\% 17,2$ & $\% 6,6$ & $\% 10,33$ & $\% 7,67$ \\
\hline $\begin{array}{l}\text { Codon } 8(-A A), \\
\text { c.25.26.delAA }\end{array}$ & $\% 4,1$ & $\% 6,44$ & $\% 7,7$ & $\% 4,69$ & $\% 9,15$ \\
\hline Codon $44(-\mathrm{C})$ & $\% 4,1$ & $\% 2,15$ & $\% 1,3$ & $\% 1,78$ & $\% 4,95$ \\
\hline Hb F Carlton & $\% 3,1$ & - & - & - & - \\
\hline Cd 5 [-CT], c.17.18delCT & $\% 3,1$ & $\% 1,07$ & $\% 1,9$ & $\% 1,22$ & $\% 2,97$ \\
\hline $\begin{array}{l}\text { cd8/9+G, c.27_28insG, } \\
\text { c.27dupG }\end{array}$ & $\% 3,1$ & - & - & - & - \\
\hline $\begin{array}{l}\text { c.364 G>A, p.Glu122Lys, } \\
\text { Hemoglobin O (ARAB), } \\
\text { Hemoglobin EGYPT }\end{array}$ & $\% 3,1$ & - & - & - & - \\
\hline c. $-31 \mathrm{C}>\mathrm{T}$ & $\% 3,1$ & - & - & - & - \\
\hline CD6-A, c.20delA & $\% 3,1$ & - & - & $\% 0,64$ & - \\
\hline $\begin{array}{l}\text { C. }^{*}+111 A>G \\
(\text { PolyA })(A>G)\end{array}$ & $\% 2$ & - & $<\% 0.1$ & $\% 0,56$ & - \\
\hline $\begin{array}{l}\text { IVS-II-1 }(G>A), c .315+1 \\
G>A\end{array}$ & $\% 1$ & $\% 2,15$ & $\% 7,2$ & $\% 8,08$ & $\% 6,43$ \\
\hline $\begin{array}{l}\text { c.30.31insT, } \\
\text { p.Ala11Cysfs }\end{array}$ & $\% 1$ & - & - & - & - \\
\hline $\begin{array}{l}\text { CD26 G>A (Hb E), c.79 } \\
G>A\end{array}$ & $\% 1$ & & & & \\
\hline CD15 G>A, c.48 G>A & $\% 1$ & & & & \\
\hline
\end{tabular}

Dünya nüfusunun \%5,2'sinin (360 milyon bireyden daha fazla) bir hemoglobin varyantı taşıdığı ve $\% 1,5$ sıklıkta beta talasemi taşıyıcııı̆ı olduğu tahmin edilmektedir. Türkiye'de beta talasemi taşıyıcılığı \%2 olarak bildirilmektedir. Bölgesel farklılıklar göstermekle birlikte Antalya'da \%5,7$10,7(9,10)$, Muğla'da \%3,8 (11), Kuzey Kıbrıs'ta $\% 14,3$ (3), Elbistan bölgesinde \%0,9 (12), Doğu Anadolu'da \%0,6 (13), Denizli'de \%3,6 (14), Bursa'da \%2,6 (15), Van'da \%2,6 (16), İzmir'de $\% 2,1-3(17,18)$, Batı Trakya'da \%10,7 (19) sıklıkta bildirilmiştir. Tablo-2'de çalışmamızda saptanan beta talasemi mutasyonları diğer bölgeler ile karşılaştırılmıştır. Türkiye genelinde akraba evliliğinin sık olması ve nüfustaki hızlı artış, beta talasemili birey sayısının fazla olmasının sebepleridir. Türkiye'de yaklaşık 1,5 milyon talasemi taşıyıcısı ve yaklaşık 5500 talasemi ve diğer hemoglobinopatilere sahip olan hasta bulunmaktadır (4).

Türk populasyonunda beta talasemi kliniğine yol açan moleküler mekanizmalar heterojen yapı göstermektedir. IVS I.110 pek çok çalışmada, en sık görülen mutasyon olarak bildirilmiştir. Diğer 
mutasyonların sıklığı bölgesel farklılıklar göstermektedir. Türkiye genelinde yapılan bir çalışmada Türkiye genelinde beta talasemi mutasyon çeşitlerinden en sık IVS I.110, ardından IVS I.6, Codon 8, IVS I.1 ve -30 (T>A) (HBB: c. $80 T>A$ ) mutasyonlarının izleyen sıklıkta görüldüğü bildirilmiştir (20). Çukurova bölgesinde yapılan başka bir çalışmada IVS I.110 yine en sık görülürken, Codon 8, IVS I.1 ve IVS I.6 diğer sık görülen mutasyonlar olarak bildirilmiştir (21). IVS I.110 tüm Türkiye'de $\% 40$ sıklıkta bildirilmiş olup (22), bizim çalışmamızda da benzer şekilde IVS I.110 en sık görülürken, Codon 39, IVS II.745, IVS I.6 sırasıyla diğer sık görülen mutasyonlar olarak belirlendi.

Bizim çalışmamızda mutasyon saptadığımız olgularda beta talasemi minor kliniği mevcuttu ve sonuçları bu klinikle uyumlu olarak saptandı. Bileşik heterozigot ve homozigot genotiplere sahip bireylerde klinik durum, hemoglobinopatiyi tanımlamak açısından yol göstericidir. Bir olgumuzda bileşik heterozigotluk (Codon 39 (C>T) ve $\mathrm{Hb}$ F-Carlton) mevcuttu, kliniği ile birlikte değerlendirildiğinde beta talasemi minor tanısı aldı. Kesin tedavisi olmayan bu hastalık için yapılabilecek en kesin çözüm hastalığın ortaya çıkmasını önlemek olacaktır.

\section{Sonuç}

Yaptığımız bu retrospektif çalışmada, Trakya Bölgesindeki beta talasemi mutasyon sıklığını ve çeşitlerini tanımladık ve 97 olguda on sekiz farklı mutasyon saptadık. Talasemi ve diğer hemoglobinopatiler gibi kalıtsal hastalıklar açısından yüksek risk taşıyan toplumlarda genetik danışma, prenatal tanı testleri ve populasyon taramaları büyük bir öneme sahiptir. Riski yüksek çiftlere tarama programları sayesinde ulaşmak ve bunun sonucunda bu çiftlere genetik danışma vermek gelecek kuşaklardaki hastalık oranını azaltabilecektir.

\section{Kaynaklar}

1. Tadmouri GO, Başak AN. $\beta$-thalassemia in Turkey; A review of the clinical epidemiological molecular and evolutionary aspects, Hemoglobin 2001; 25 (2): 227-39.

2. Özkınay F, Onay H, Karaca E, Arslan E, Ertürk B, Ece Solmaz A, et al. Molecular Basis of $\beta$-Thalassemia in the Population of the Aegean Region of Turkey: Identification of A Novel Deletion Mutation. Hemoglobin. 2015; 39 (4): 230-4. doi: 10.3109/03630269.2015.1038354. Epub 2015 Jun 15.

3. Galanello R, Origa R. Beta-thalassemia. Orphanet J Rare Diseases 2010; 5: 11

4. Canatan D. Thalassemias and hemoglobinopathies in Turkey. Hemoglobin. 2014; 38: 305-7.

5. Rund D, Rachmilewitz E. Pathophysiology of Alpha and Beta - thalassemia: Therapeutic implications. Sem Hematol, 2001; 38 (4): 343-9.

6. Christianson A, Howson CP, Modell B. The hidden toll of dying and disabled children. March of Dimes Global Report on Birth Defects. March of Dimes Birth Defects Foundation, White Plains, NY, USA; 2006.

7. Modell B, Darlison M. Global epidemiology of hemoglobin disorders and derived service indicators. Bull World Health Organ. 2008;86(6):480-7.

8. Ansari SH, Shamsi TS. Thalassaemia Prevention Programme. Haematology Updates. 2010; 23-8.

9. Aksoy M, Dinçol G, Erdem S. Survey on Hb variants, beta-thalassemia, G6PD deficiency and hain haptoglobin types in Turkish people living in Manavgat, Serik, Boztepe (Antalya). Human Heredity 1980; $30: 3$.

10. Bircan I, Sişli S, Güven A, Cali S, Yeğin O, Ertuğ H et al. Hemoglobinopathies in the district of Antalya, Turkey. Pediatr Hematol Oncol 1993; 10: 289-91.

11. Arcasoy A, Turan F, Yeşil N, Kemahlı S, Uysal Z, Canatan D, ve ark., et al. Muğla ili ve çevresinde thalassemia ve anormal hemoglobin sıklığının taranması. Pediatride Yönelişler 1994;1: 78-81.

12. Canatan D, Arcasoy A, Bor S, Yeşil N. Elbistan yöresinde anormal Hb ve HbA2 yüksekliği ile karakterize Bthalassemia taşıyıcı taraması. Doğa Bilim Der 1990; 14: 555-61.

13. Kürkçüoğlu M, Dağcı AY, Arcasoy A, Ağbaş A. Doğu Anadolu bölgesinde beta talasemi taraması. Doğa Bilim Dergisi 1986; 8: 319-25.

14. Sözmen M, Uysal Z, Yeşil N, Akar N, Arcasoy A. Denizli'de anormal hemoglobinler ve Hb A2 yüksekliği karakterize beta-talasemi taşıyıcılığı araştırması. Ankara Tıp Fakültesi Mecmuası 1990; 43: 959-64. 
15. Akar N, Uysal Z, Yeşil N, İnce E, Arcasoy A. Mustafakemal Paşa ve köylerinde anormal hemoglobinler ve Hb A2 yüksekliği karakterize beta-talasemi taşıyıcılığı araştırması. Doğa Bilim Dergisi 1990;14: 551-4.

16. Aksoy $\mathrm{H}$, Bayraktar $\mathrm{Y}$, Yüzbaşığlu $\mathrm{T}$. Frequencies of abnormal hemoglobins high $\mathrm{A} 2$ beta thalassemia and distribution of haplotypes in Turks living in Van and its vicinities, Eastern Turkey. Doğa Bilim Dergisi 1986; 10: 1-4.

17. Aydınok Y, Öztop S, Nişli G, Kavaklı K. Prevalence of beta-thalassaemia trait in 1124 students from Aegean region of Turkey. J Trop Pediatr 1997;43: 184-5.

18. İrken $\mathrm{G}$, Ören $\mathrm{H}$, Ündar $\mathrm{B}$, Duman $\mathrm{M}$, Gülen $\mathrm{H}$, Uçar $\mathrm{C}$ et al. Analysis of thalassemia syndromes and abnormal hemoglobins in patients from the Aegean region of Turkey. Turk J Pediatr 2002; 44: 21-4.

19. Aksoy M, Kutlar A, Kutlar F, Dinçol G, Erdem Ş, Baştesbihçi S. Survey on hemoglobin variants beta-thalassemia, G6PD deficiency and haptoglobulin types in Turks from Western Thrace. J Med Genet 1985; 22: 288-90.

20. Altay C. The frequency and distribution pattern of b-thalassemia mutations in Turkey. Turk J Haematol. 2002; 19 : $309-15$.

21. Yüzbasıoğlu Arıyürek S, Yıldız SM, Yalın AE, Güzelgül F, Aksoy K. Hemoglobinopathies in the Çukurova region and neighboring provinces. Hemoglobin. 2016; 40: 168-72.

22. Fettah A, Bayram C, Yarali N, Isik P, Kara A, Culha V, et. al. Beta-globin Gene Mutations in Turkish Children with Beta-Thalassemia: Results from a Single Center Study. Mediterr J Hematol Infect Dis. 2013 Sep 2;5(1):e2013055. doi: 10. 4084/MJHID.2013.055. eCollection 2013. 